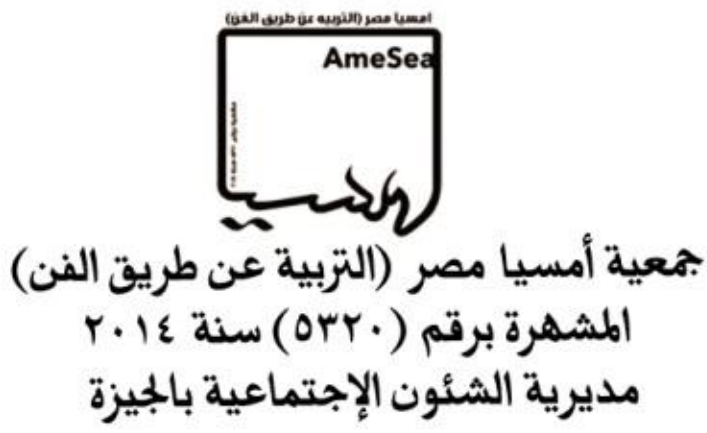

\title{
THE PERSPECTIVES OF EDUCATORS ABOUT USING MUSIC WITH STUDENTS WITH DISABILITIES
}

College of Basic Education

Dr. Haya Eshaq 


\begin{abstract}
The goal of this study was to explore the need of using music with students with disabilities to improve their skills. In order to address the issue of lack of research about music education in Kuwait for students with disabilities, the current study proposed to investigate teacher perceptions on two major questions: (a) How is music education used with students with disabilities in elementary classrooms and (b) What are the perceptions of teachers toward using music education with students with disability in elementary classrooms? This study was significant for two reasons. First, the current literature regarding music programs for students with disabilities in the regular classrooms in Kuwait's schools was lacking in providing enough information for researchers and educators to build on. Second, there was a severe need to improve the current programs to increase the performance of students with disabilities in regular classrooms.
\end{abstract}

There were three participants in this study. One special education teacher and two music teachers from different Kuwaiti schools were interviewed about using music with students with disabilities in the classroom. Results showed that all the participants had a positive impression about using music with special needs and felt that music was very helpful in increasing the performance and behavior skills of students with disabilities. Participants asked to be given more information about using music and having enough musical instruments and training from the Ministry of Education in Kuwait. 


\section{Introduction}

Music education is an important part of a general education program. Every child deserves to have access to a high-quality music education. However, many obstacles create barriers for the educator teaching children with disabilities. "Disability" is a very general term that can mean a variety of things ranging from physical impairments, such as vision loss, hearing loss, paralysis, to learning disabilities, mental retardation, or emotional disorders. How do these disorders affect one's ability to participate in music instruction? It is noteworthy to mention that Johann Sebastian Bach and Ludwig von Beethoven both became disabled later in life and continued to produce masterpieces (Abramo, 2012). Bach became completely blind and continued to write the Art of the Fugue. After Beethoven became deaf, he composed many of his most famous works such as Symphony No. 9. Recent neuroscience has confirmed that people with disabilities often have exceptional abilities in other areas. For example, individuals who are blind have more accurate pitch perception and spatial placement of sound (Abramo, 2012). Individuals with autism have a higher rate of perfect pitch than their non-autistic counterparts (Abramo, 2012). Therefore, it is important not to assume that because children have a disability, they will have a lower level of performance than their non-disabled peers.

These facts serve to suggest the value of including children with disabilities in the music classroom, even though the concept of inclusion in a general music education program may seem daunting. However, there are many ways successfully to incorporate students with disabilities in a way that benefits everyone. Simple modifications may be made that any music instructor can easily incorporate, either alone or with the assistance of a special education instructor. Whereas schools in the United States have made great advancements in the inclusion of students with 
disabilities in music classes, my home country of Kuwait has much to do in order to accomplish this.

The literature lacked research in the effectiveness of music therapy with children with disabilities in Kuwait's schools. Currently in Kuwait, students with disabilities are not typically exposed to music therapy. Educators in Kuwait need more effective strategies including music therapy to intervene with those students. Research, which has been done in American schools, demonstrated the effectiveness of using music in improving the performance of children with disabilities. Understanding the need of using music with students with disabilities to improve their skills would allow educators and researchers to do more research on this topic and apply music therapy through the curriculum. Different types of music therapy can help to increase important life skills including social, emotional, communicative, cognitive, and behavioral skills (Langan, 2009), and this could help students with disabilities in Kuwaiti schools.

In order to address the issue of lack of research about music education in Kuwait for students with disabilities, the current study proposed to investigate teacher perceptions on this topic. Two major questions are stipulated: (a) How is music education used with students with disabilities in elementary classrooms and (b) What are the perceptions of teachers toward using music education with students with disability in elementary classrooms? This study was significant for two reasons. First, the current literature regarding music programs for students with disabilities in the regular classrooms in Kuwait's schools was lacking in providing enough information for researchers and educators to build on it. Second, there was a severe need to improve the current programs to increase the performance of students with disabilities in regular classrooms. The purpose of this phenomenological study was to explore the teacher's perspective about the use of music with students with disabilities in Kuwaiti's schools. 


\section{Literature Review}

Every child is unique and different disabilities require different types of adaptations. Likewise, different disabilities may be perceived differently by music instructors. This review considers necessary adaptations and teacher perceptions for both physical and mental disabilities. It gives some general considerations for working with a child of any disability.

\section{Physical Disabilities}

A survey of 221 high school music programs in Nebraska suggested that program directors were not knowledgeable about the availability of adapted instruments for students with physical disabilities and that they were concerned about receiving funding for those instruments (Nabb \& Balcetis, 2010). In contrast, Darrow (2012) suggested that many adaptations to instruments could be made easily and inexpensively. He suggested that the most common adaptations included "touch-sensitive pads, Velcro straps, large knobs, stands to hold instruments, and color-coded music systems" (para. 2).

Knapp (2011) has suggested that taiko drums were a good choice for hearing impaired children. The strong beat provided a rhythm that could be felt and the choreography allowed the child to visually follow the movements. It was estimated that Japan had over 50 taiko ensembles for the hearing impaired.

\section{Mental Disabilities}

Heikkila and Knight (2012) described several reasons that music educators may be uncomfortable working with children with developmental dyslexia (DD). These included misconceptions about the nature of DD, an inability to see the practical application of research on DD to teaching music and limited amounts of undergraduate training in special education. 
Even so, Heikkila and Knight suggested that music educators can easily teach children with DD with only limited knowledge about DD.

Price (2012) suggested specific modifications that could be made to accommodate children with emotional disturbances. He suggested that an effective strategy requires the music educator to be completely prepared ahead of time, placing the children with emotional disturbance in plain sight. He discussed how music class may seem somewhat chaotic by nature and that this in of itself could create discomfort and possibly misbehavior in some children. Music instructors may feel uncomfortable working with these children, again because of their limited proficiency in special education. However, music teachers may collaborate with special education instructors to ensure that students receive the optimal level of instruction.

\section{General Considerations}

Three categories of adaptations in working with a child of any disability include behavioral, motivational, and organizational adaptations (McDowell, 2010). Behavioral adaptations include knowing specific behavioral reinforces for each child, removing instruments if necessary, giving clear, uncomplicated directions, and moving the student closer to the teacher. Motivational adaptations may include recognizing a child's musical strength and developing leadership ability with that, allowing a student to choose an instrument to play a particular song, and allowing a student to conduct a song. Organizational adaptations include asking a student to perform one task at a time, having the student join in on the repeating part of a song, and have the student sit next to an effective singer and have them match the voice.

\section{Summary}

Children with disabilities present a range of challenges for integrating them into the music classroom. Music instructors typically have multiple concerns with how to incorporate 
such students successfully. However, with the proper resources, any music instructor could effectively and successfully encourage the participation of all students with disabilities into the music classroom.

\section{Methodology}

In this study, I used a qualitative approach to investigate the focus of the study. Qualitative research is a type of research that is theoretically, methodologically, and analytically different from quantitative research. From a theoretical perspective, qualitative research grew out of grounded theory and is summarized succinctly by Lincoln and Guba (1985) in their treatise Naturalistic Inquiry. Lincoln and Guba first described the theoretical basis of qualitative research, later described by Creswell (1998), as an alternative approach to the objective stance of quantitative positivists and include such precepts as multiple perspectives, the impossibility and lack of value of achieving a single objective truth, and an entirely different methodology which demands that the research construct a holistic, complex multi-dimensional representation using word analysis, detailed perspectives of participants and informants, and conducted in natural settings in order to explore human or social problems. In order to best address the problem of my study, a qualitative inquiry provided a better understanding of a phenomenon. It relies on an in-depth analysis of emerging themes while engaged with few participants (versus studying and quantifying responses of subjects) (Creswell, 1998). Moreover, qualitative research works in interpreting different variables and reveals their connectivity, how they relate to each other, and how they work in a holistic form (Merriam, 1998).

\section{Researcher Personal Stance}

I believe in the importance of improving the use of music in regular classrooms in Kuwaiti's schools to improve students with disabilities performance to the goal was to explore 
the different views by different educators who worked with students with disabilities regarding the use of music strategies to improve students' performance.

\section{Participants}

Three teachers from public schools participated in this study. Since I started to investigate the perspective toward using music with students with disabilities, participants were selected based on these criteria: special and music education teachers who worked with students with disabilities in different schools. I used a purposeful, convenient sampling technique to select the participants. As indicated in Merriam (1998), purposive sampling is a procedure where a sample is taken from a pre-selected population that has already been determined to produce the most learning, based on investigator desires to discover, understand, and gain insight. Purposive sampling or judgment sampling served to answer my research questions. Merriam categories sampling as convenient when selecting participants based on availability.

The following three teachers participated in this study. My first participant was with Ms. Sara who was the special education teacher with 4 years of experience teaching students with disabilities. The second participant was Mr. Hamid who was a music teacher with 10 years of experience teaching students with special needs. The third participant was Ms. Dana who was another music teacher and spent 6 years with students with special needs. All the participants worked in different elementary schools.

\section{Procedures}

After obtaining the contact information for each teacher, they were contacted by phone and by emails. After receiving their initial permission to participate, I confirmed that each participant met the criteria that I had established. Afterwards, a soft copy of the consent form 
explaining the purpose, the interview time, and the procedures of the study was sent to them. They also were given the opportunity to save a copy of the consent form for their reference.

Interviews were conducted by phone. Two time options were provide to each participant to choose from in order to arrange for the most appropriate time to conduct the interview. Once I finished my interview with the participants, I asked them whether they knew of other professionals who could participate in my study. This strategy, known as snowballing or network strategy, assisted in recruiting more participants. I asked each participant to refer me to other professionals who met my criteria (Merriam, 1998). Snowballing includes identifying "cases of interest from people who know people who know people who know what cases are informationrich; that is, good examples for study, good interview subjects" (Patton, 1990, p. 182). I interviewed one special education teacher who had worked as a teacher for 3 years and two music teachers, one who has worked for 10 years and the other for 4 years.

After obtaining the approval from the university's Institutional Review Board, consent forms were distributed among the study participants, which included a description of the purpose of the study. I used semi-structured in-depth interviews. Interviews are essential when investigating feelings, thoughts, how people perceive certain world events, and past experience (Merriam, 1998).

\section{Data Collection}

Data were collected from the interviews which were recorded and transcribed. The interviews consisted of 8 to 10 questions (see Appendix). Each interview lasted approximately 45 minutes. Participants' names have been kept confidential. Only the researcher who conducted the interviews had access to any information shared during the interview process. 


\section{Data Analysis}

Interpretivism was the guiding theoretical perspective used in the analysis of data obtained from the interviews, in order to look for interpretations that would be sensitive to culture and historically situated (Crotty, 2004). After each audio-taped interview was completed, they were transcribed and then stored electronically. Then, the data were analyzed from a qualitative perspective. Each transcript was read and reread to extract common themes among the responses of the participants. The identity of the participants was kept confidential throughout the data analysis by using their first name initial to maintain anonymity.

Trustworthiness was enhanced by using questions already generated by previous research (Merriam, 2009). Member checks were conducted to verify respondent validation, and credibility was addressed by in-depth engagement in data collection and analysis. Also, I maintained a constant awareness of my own biases and position, in order to control for researcher's position. Consistency, rather than reliability, was sought by examining the data that were collected and determining that the results were consistent. Transferability was maximized by providing thick, rich descriptions that contained very descriptive and detailed information related to the findings.

\section{Findings}

My research sought to investigate the perspectives of teachers in Kuwait who worked with students with disabilities regarding the role of music education with these students. In this study, I analyzed the data based on the following two research questions: (a) How is music education is used with students with disability in elementary classrooms and (b) What do teachers perceive as the use of music education with students with disability in elementary classrooms? 
As I examined the data, the theme regarding the nature of using music education with students with disabilities emerged, which addressed the first question. In answer to the second question, a second theme arose which revolved around educators' perception regarding the use of music education with students with disabilities.

My participants consisted on one special education teacher (Ms. Sara) and two music teachers (Mr. Hamid and Ms. Dana. The participants were all from different elementary schools.

\section{Theme 1: The Nature of Using Music Education with Students with Disabilities}

Ms. Sara talked about her experience of using music with students with special needs in her regular classrooms. She replied, "I use music in all the academic activities with the students with special needs." She also provided examples of using music in her classroom: "I use chant with students with special needs in the [special] classroom because I feel that music stimulates the student to participate with me and increase their concentration and attention during the lesson." She gave the following example from her experience:

If the student is distracted in his attention with me, directly I use any musical sounds as an alert to make an attention, so all these in music helps the teacher and leave a good effect for the student with disability, and I can't give any lessons without using music in my class.

Mr. Hamid also talked about his experience as a music teacher in the elementary school with students with special needs: "It is a great opportunity and very important to collaborate using music with students with special needs because music helps students with special needs to sing and pronounce the words, think about the education lesson while they sing." He continued by giving this example: "For the blind students, one lesson was about brushing their teeth and how to be clean; they sing a song about how to be clean and how to wash or brush their tooth and do many gestures while they sing and think about the cleaning." 
Ms. Sara expanded on the types of music that she used in her classroom: "I use my voice, the maracas percussion instrument a lot in the class. Also I use records or iPad devices. For instance, I record or download different music sounds from the Internet or songs." She also added, "In addition, I use the triangle instrument in the class, and the bell with every instrument makes sound."

Moreover, Mr. Hamid said, "I try to involve them to learn and play music." While Ms. Dana who was a music teacher in another elementary school said, "I love to bring out the best talent of the students with special needs because they have a great talent in music, and I taught many students with special needs which showed a brilliant talent in music.” Additionally, Ms. Sarah mentioned, "music as individual effort not as a special curriculum" and Mr. Hamid said, "I used our curriculum, but it is not very strong having a good idea of using music with disabilities, so I create my ideas individually to have more positive results." Likewise, Ms. Dana said, "I use and create my ideas individually."

Ms. Sarah also thought that music could improve students' skills in the following areas: "Music supports in the development of many of the students' skills." And she continued with her example, "There are students who love to sing so that when I start the music the students with special needs, they directly engage with me and sing, memorize words effectively, and remembered the melody of the chant." Also Ms. Dana gave the same idea when she said, "Create a musical chant to be useful with other academic subjects that can help to consolidate the information in the student's mind." Additionally, Hamid said, "I try to challenge the student to play the musical instruments like Org, xylophone, percussion instruments, and singing, and it is dependent on the level of the student's distraction." 
Ms. Sarah highlighted a very interesting point when she said, "It will take a long time to teach the students with special needs without using music in their academic and their movement skills." Through her successful experience, she used music with a student with autism who had very severe special needs, and as a result of her experience she said, "When I used the music every day with this student, I recognized that the student increased his attention with the chant and music." She continued by saying, "When the melody of the sun started, he ran and pointed to the picture of the sun, and when he heard the melody related with athleticism, he started to do some movements like moving his body right and left, down and up." Also from her experience, she added:

Every education lesson, I used appropriate music with students with special needs. For example, if the lesson has an education movement, I used joy music or if the lesson has education story, I used a quite music as a background and some alert sounds related to the story, so every different aspect, I used an appropriate music.

She mentioned particularly, "Especially the blind students are the students who most like and make attention with music." Ms. Dana has the same thought of the blind students when she said: "One of my blind student who was very sad and had a shaky confidence. I taught him to play music melody for a music competition between the schools." After the blind student practiced with playing the Org for 3 months she said,

He surprised me with his high fascination capacity and excellent playing, and his helps the student to increase his self-confidence and he was happy and proud of himself. Additionally, he loved the music and to play the org instrument, and also joined the music team. 


\section{Theme 2: Educators' Perspective Regarding Using Music Education with Students with Disabilities}

Ms. Sara pointed out that, "Music education is very important for students with special needs; for example students with physical needs, hearing impaired, blind, Autism, and Down syndrome.” It was not very different from what Ms. Dana said, “ Music in special education gives the student with special need confidence through integration with classmates through singing song, plying music, and using the academic music games.” Also, Mr. Hamid mentioned that "the students with special needs have a great and strong relationship with music, and we have to use it properly to improve their academic performance." Through my conversation with Ms. Sarah, she said, "The student can express his feelings by either motor movements or psychologically through music, and it helps him to overcome some psychological distress felt." Moreover, Mr. Hamid said, “The first results after using music with students with disabilities are reducing the motor activity of the students, developing their attention to the lesson, and reducing the students' level of distraction." He presented an example of his point by stating, "One of my students who had an attention deficit-hyperactivity disorder (ADHA), when I let him join the music group, then music decreased the hyperactivity and increased his attention."

Ms. Sarah continued her conversation by stating, "All teachers who are with me in the same major use music in their classes, because they are sure that music will help the students with special needs adjust with the teacher in a positive way." Similarly, Ms. Dana said, "All the teachers agree and support the using of music with students with disabilities, and they always try to have some help from the music teacher." Also, Hamid gave the same thought when he said, "All other teachers support the use of music with students with disabilities, and this is very encouraging." Moreover, Mr. Hamid mentioned a very interesting fact when he said, "We need 
more special instruments for the students with special needs because there is limited of using variety musical instruments in the music class." Also he continued, "The Ministry of Education should increase the training for music teachers to understand how to deal in academic way with students with special needs."

\section{Discussion}

The purpose of this study was to explore the teachers' perception about the use of music with students with disabilities in Kuwaiti's schools. In examining the responses of the teachers, some common ideas were shared by all the teachers.

The findings showed in the first theme that all the participants were in agreement that music was very important for the students with special needs in their classrooms and was supported by Abramo (2012). Also, in the same study of Abarmo, the blind had more accurate pitch perception and spatial placement of sound, and this was similar to what the two music teachers mentioned. In addition, the participants observed that the attention and behavioral skills of students with disabilities were increased when they used music in their lessons, which was consistent with Langan‘s (2009) study when he mentioned the different types of music that could help to increase important life skills including social, emotional, communicative, cognitive and behavioral skills.

Another result of my finding was that the participants wanted more collaboration between music and special education teachers, which was consistent with the Price (2012) study about how music teachers may collaborate with special education instructors to ensure that students received the optimal level of instruction. In addition, all the participants were in agreement that singing helped a lot in the development of words and conversation of the students with special needs, supporting McDowell’s (2010) findings. 
In the second theme of the findings, the participants stated that music could change the students with special needs in terms of emotions and behavior into a better level. This finding supported the study by Walker (1996) which showed that all children could be assisted in learning to enjoy and become involved in music in some level and that music could be a great value for children who had difficulties in hearing, seeing, moving, thinking or responding. Additionally, what the participants showed through the findings was that the limited availability of the special musical instruments for the students of special needs corresponded with two studies (Darrow, 2012; Nabb \& Balcetis, 2010) when they mentioned the availability of adapted instruments for students with physical disabilities and that they were concerned about receiving funding for those instruments.

Furthermore, the participants asked to have more training for the music teachers from Kuwait Ministry of Education in order to have more understanding of how to deal in academic methods with students with special needs. This also supported the study by Heikkila and Knight (2012) when they mentioned that there was a limited amount of music undergraduate training in special education.

\section{Recommendations and Implications}

It is recommended, based on the information obtained in this study, that Kuwait schools use more music instruction to support the teacher's ideas of using music with students with disabilities and present more instructions to guide them in their curriculum. Moreover, the Ministry of Education in Kuwait must provide more training in music education for general and music education teachers that could help the teachers to reach a higher level of understanding of how to deal with students with special needs. It seems that Kuwait needs more collaboration between the special education teachers and music education teachers to provide solid instruction 
to students with special needs. Also, the participants suggested getting more special instruments for students with special needs; for example, different types of percussion instruments, different size of strings instruments, and more keyboards for students to use.

The participants in this study recommended that all students with special needs should be involved in music competitions, not only the best student in the groups. Besides that, it was very encouraging for both students with special needs and teachers to have the parents' support for the use of the music with their children with special needs.

Using music in special Kuwaiti Schools made a tangible difference to the relationship between teachers and the students with special needs. A big part of it was that the Kuwaiti special education teachers felt more motivated and optimistic as a result of using music in their teaching and caregiving. They were able to communicate better with the students once they had learned strategies like taking the lead from the student and going a little bit slower to allow time for a response by using music education through their class with students with disabilities. Furthermore, Kuwaiti music teachers know that using music with students with disabilities could lead them to explore the internal power of the students with special needs, which Ms. Dana believed was bring out the best talent of the students with special needs.

Finally, I want to end with what Ms. Sarah said, "I am sure if I did not use music with the Autistic students, his [academic] skills will not improve, so the music was very helpful." 


\section{References}

Abramo, J. (2012). Disability in the classroom: Current trends and impacts on music education. Music Educators Journal, 99(1), 39-45. doi:10.1177/0027432112448824

Creswell, J. W. (1998). Qualitative inquiry \& research design: Choosing among five approaches. Thousand Oaks, CA: Sage.

Darrow, A. (2012). Adaptive instruments for students with physical disabilities. General Music Today, 25(2), 44-46.

Heikkila, E., \& Knight, A. (2012). Inclusive music teaching strategies for elementary-age children with developmental dyslexia. Music Educators Journal, 99(1), 54-59. doi:10.1177/0027432112452597

Knapp, D. H. (2011). The inclusive world of music: Students with disabilities and multiculturalism. General Music Today, 25(1), 41-44. doi:10.1177/1048371311414183

Langan, D. (2009). A music therapy assessment tool for special education: Incorporating education outcomes. Australian Journal of Music Therapy.

Marshall, M. N. (1996). Sampling for qualitative research. Family Practice, 13(6), 522-525.

McCord, K., \& Watts, E. H. (2006). Collaboration and access for our children: Music educators and special educators together (cover story). Music Educators Journal, 92(4), 26-33.

McDowell, C. (2010). An adaption tool kit for teaching music. Teaching Exceptional Children Plus, 6(3), 1-18.

Merriam, S. B. 1998. Qualitative research and case study applications in education. San Francisco, CA: Jossy-Bass. 
Nabb, D., \& Balcetis, E. (2010). Access to music education: Nebraska band directors' experiences and attitudes regarding students with physical disabilities. Journal of Research In Music Education, 57(4), 308-319. doi:10.1177/0022429409353142

Price, B. S. (2012). Zero margin for error: Effective strategies for teaching music to students with emotional disturbances. Music Educators Journal, 99(1), 67-72. doi:10.1177/0027432112451620

Walker, A. (1996). An ear for music. In J. Piotrowski (Ed.), Expressive arts in the primary school (pp. 38-48). London, England: Cassell. 